\title{
Tackling diabetes: how nurses can make the difference
}

Hicham El Berri, ${ }^{1}$ F Gulin Gedik, ${ }^{2}$ Jamal Belkhadir, ${ }^{3}$ Howard Catton, ${ }^{4}$ Asmus Hammerich, ${ }^{5}$ Arwa Oweis ${ }^{6}$ and Slim Slama ${ }^{7}$

${ }^{1}$ Medical Officer for NCD Management, Department for UHC/Noncommunicable Diseases and Mental Health, World Health Organization Regional Office for the Eastern Mediterranean, Cairo, Egypt. ${ }^{2}$ Coordinator, Health Workforce Development, World Health Organization Regional Office for the Eastern Mediterranean, Cairo, Egypt. ${ }^{3}$ Regional Chair, International Diabetes Federation Middle East and North Africa, Rabat, Morocco. ${ }^{4}$ Chief Executive Officer, International Council of Nurses, Geneva, Switzerland. ${ }^{5}$ Director, Department for UHC/Noncommunicable Diseases and Mental Health, World Health Organization Regional Office for the Eastern Mediterranean, Cairo, Egypt. ${ }^{6}$ Regional Advisor, Nursing and Midwifery, World Health Organization Regional Office for the Eastern Mediterranean, Cairo, Egypt. ${ }^{7}$ Regional Advisor for Noncommunicable Diseases Prevention, Department for UHC/Noncommunicable Diseases and Mental Health, World Health Organization Regional Office for the Eastern Mediterranean, Cairo, Egypt. (Correspondence to: Hicham El Berri: elhi@who.int).

Citation: El Berri H; Gedik FG; Belkhadir J; Catton H; Hammerich A; Oweis A; et al. Tackling diabetes: how nurses can make the difference. East Mediterr Health J. 2020;26(11):1318-1319. https://doi.org/10.26719/2020.26.11.1318

Copyright (C) World Health Organization (WHO) 2020. Open Access. Some rights reserved. This work is available under the CC BY-NC-SA 3.0 IGO license (https://creativecommons.org/licenses/by-nc-sa/3.o/igo).

This year, World Diabetes Day on 14 November coincides with the International Year of the Nurse and the Midwife, and therefore focuses on highlighting the role of nurses in the prevention and management of diabetes.

Diabetes is recognized as an important cause of premature death and disability globally and in the Eastern Mediterranean Region, where its prevalence has been steadily increasing since 1990, (1). Although the annual decline of the risk of dying from a major noncommunicable disease between the ages of 30 and 70 years is slowing globally, diabetes is showing a $5 \%$ increase in attributed premature mortality (1). In 2016, diabetes was the direct cause of 1.6 million deaths globally and $43 \%$ of all deaths before the age of 70 years occur due to high blood glucose (2). Overweight and obesity are the strongest risk factors for type 2 diabetes $(3,4)$. In addition, diabetes increases the risk of heart disease and stroke and is a leading cause of blindness, lower limb amputation and kidney failure. A study conducted in 35 countries indicated that people living with diabetes are more likely to experience catastrophic health expenditures with an estimated increase of $4 \%$ between diabetic and nondiabetic individuals, regardless of their insurance status (5).

The Eastern Mediterranean Region has the highest rates of diabetes worldwide with more than 43 million people living with the disease (1). Many countries in the Region are struggling to meet the health-care needs of people with chronic diseases. Diabetes and its complications are a great economic challenge in advancing universal health coverage. Several obstacles exist in terms of organization of health and care systems to prevent and manage diabetes, including insufficient public investment, shortage of health workers, lack of availability and accessibility of medicines, and insufficient information for decision-making (6). In addition, the COVID-19 pandemic has taught us how vulnerable our systems are in terms of preparedness and imposed challenges to the provision of care for patients with diabetes $(7,8)$.

Health workforce shortages in the Region have a significant impact on the availability and accessibility to services, which implies the need for interventions to maximize their functions and performance in addressing the 5.9 million of shortage of nurses, $17 \%$ of which is in the Region (9). Health workers, at primary care level, play an important role in prevention and management of non-communicable diseases including diabetes. Nurses, as the largest group of health-care providers and the point of first contact, should take a leading role in diabetes detection, treatment and rehabilitation, as well as supporting health promotion and prevention efforts to people living with diabetes, thus allowing them to participate in the decision-making regarding diabetes care.

While recognizing that adequate numbers of welleducated nurses are key to maintaining essential health services to effectively address the rise in noncommunicable diseases including diabetes, the need for strengthening the nursing workforce in the Region remains as a challenge. Increases in numbers have not been sufficient to match population growth; moreover, there has even been a decline in nursing numbers in almost half of countries in the Region since $2010(10,11)$, affecting nurses' ability to perform in their full capacity and scope of practice. Diabetes care should also be reviewed in nursing training and updated in accordance with recent developments. Furthermore, nursing leadership in policy and advocacy is imperative to change practice and expand nursing capacity to address diabetes in the Eastern Mediterranean Region (12). It is essential that nurses take on this leadership role in a more assertive way, working with decision-makers to achieve positive health outcomes and provide an effective quality of care at a lower cost (13).

The nursing contribution to the health system is illustrated by six key features to prevent and manage diabetes as follows (14): 1) Care coordination to ensure that the patient's health needs are met over time; 2 ) Being part of a multidisciplinary approach to care based on an integrated relationship between health professionals, allowing different practitioners to seamlessly work as a team to improve the quality of care; 3) mobilizing and empowering the nursing workforce to specialize in 
noncommunicable diseases to improve cost-effective and sustainable treatments; 4) improving access to care; 5) empowering individuals and the community; and 6) harnessing technology to maintain access to essential health services and reduce exposure to COVID-19.

Such a situation has led Member States to call for accelerated action to strengthen nursing in the Region (15). The call for action highlights the need for investment in health workforce that impacts not only Social Development Goal 3 (SDG3) but also the other SDGs on eradicating poverty, inclusive and equitable education, gender equality through the employment and empowerment of women, and promoting decent work and sustainable and inclusive economic growth. Investments can target scaling up nursing education in terms of quantity, quality and relevance to roles and scopes of practice to maximize the utilization of their capacities, including diabetes care. Investment is also critical in creating jobs that will enable nurses to work across the full scope of practice in primary care, inpatient care settings and leadership roles where they can be available and actively involved in diabetes care (7). Investing in health workforce should be part of 'Step o' in health system recovery (16).

Overall, governments, health-care providers, civil society and individuals have a shared responsibility in raising public awareness about the threat of diabetes, its prevention and management, as well as strengthening nursing and ensuring access to acceptable standards of health care for all people living with diabetes.

\section{References}

1. World Health Organization. World Health Statistics 2020: Monitoring health for the SDGs. Geneva: World Health Organization; 2020 (https://www.who.int/gho/publications/world_health_statistics/2020/en/).

2. World Health Organization. Global report on diabetes. Geneva: World Health Organization; 2016 (https://apps.who.int/iris/bitstream/handle/10665/204871/9789241565257_eng.pdf?sequence=1).

3. Wu Y, Ding Y, Tanaka Y, Zhang W. Risk factors contributing to type 2 diabetes and recent advances in the treatment and prevention. Int J Med Sci. 2014;11(11):1185-1200. doi: 10.7150/ijms.10001 (https://www.ncbi.nlm.nih.gov/pmc/articles/PMC4166864/).

4. Bhupathiraju SN, Hu FB. Epidemiology of obesity and diabetes and their cardiovascular complications. Circ Res. 2016 May 27;118(11):1723-1735. doi: 10.1161/CIRCRESAHA.115.306825. (https://www.ncbi.nlm.nih.gov/pmc/articles/PMC4887150/).

5. Smith-Spangler CM, Bhattacharya J, Goldhaber-Fiebert JD. Diabetes, its treatment, and catastrophic medical spending in 35 developing countries. Diabetes Care. 2012 Feb;35(2):319-26. doi: 10.2337/dc11-1770. Epub 2012 Jan 11. PMID: 22238276; PMCID: PMC3263916.

6. Beran D. The impact of health systems on diabetes care in low and lower middle income countries. Current Diabetes Reports 2015;15(4):591 doi: 10.1007/s11892-015-0591-8. (https://www.researchgate.net/publication/272835492_The_Impact_of_Health_Systems_on_Diabetes_Care_in_Low_and_Lower_Middle_Income_Countries/citation/download).

7. World Health Organization Regional Office for the Eastern Mediterranean. Rapid assessment of service delivery for NCDs during COVID-19. Cairo: WHO/EMRO; 2020 (http://www.emro.who.int/noncommunicable-diseases/publications/rapid-assessment-of-service-delivery-for-ncds-during-covid-19.html?ver=2).

8. World Health Organization. Pulse survey on continuity of essential health services during the COVID-19 pandemic. Geneva: World Health Organization; 2020 (https://www.who.int/publications/i/item/WHO-2019-nCoV-EHS_continuity-survey-2020.1).

9. World Health Organization. State of the world's nursing 2020: investing in education, jobs and leadership. Geneva: World Health Organization; 2020.

10. FG Gedik, Buchan J, Mirza Z, Rashidian A, Siddiqi S, Dussault G. The need for research evidence to meet health workforce challenges in the Eastern Mediterranean Region. East Mediterr Health J. 2018.24.9.811-812. https://doi.org/10.26719.2018.24.9.811

11. World Health Organization Regional Office for the Eastern Mediterranean (WHO/EMRO). Strengthening the nursing workforce to advance universal health coverage in the Eastern Mediterranean Region, EM/RC66/R.3. 2019. Cairo: WHO/EMRO; 2019 (https://applications.emro.who.int/docs/RC66-R3-eng.pdf?ua=1).

12. Affara FA, Tuipulotu AA, Al Darazi FA, Aiken LH, Betker C, Buchan J, et al. Nurses: a voice to lead nursing the world to health. Geneva: International Council of Nurses; 2020 (https://2020.icnvoicetolead.com/wp-content/uploads/2020/03/IND_Toolkit_120320. pdf).

13. Peimano M, Tabatabaei O, Paajouhi M. Nurses' role in diabetes care: a review. Iran J Diabetes Lipid Dis. 2010;9(4):1-9 (https:// www.researchgate.net/publication/236985435_Nurses'_Role_in_Diabetes_Care_A_review).

14. World Health Organization Regional Office for the Eastern Mediterranean (WHO/EMRO). The nurse and diabetes: Report by the International Council of Nurses for World Diabetes Day 2020. Cairo: WHO/EMRO; 2020 (https://applications.emro.who.int/docs/ RC_Technial_Papers_2019_4_en.pdf?ua=1).

15. World Health Organization Regional Office for the Eastern Mediterranean (WHO/EMRO). Strengthening the nursing workforce to advance universal health coverage in the Eastern Mediterranean Region, EM/RC66/R.3. Cairo: WHO/EMRO; 2019 (https://applications.emro.who.int/docs/RC66-R3-eng.pdf?ua=1, accessed on 22 October 2020).

16. World Health Organization. UHC 2030. Living with COVID-19: Time to get our act together on health emergencies and UHC. Discussion paper, published 27 May 2020. (https://extranet.who.int/sph/sites/default/files/document-library/document/ UHC2030\%20Discussion\%20paper\%200n\%2ohealth\%2oemergencies\%20and\%20UHC\%20-\%20May\%202020.pdf, accessed on 27 October 2020). 